Chapter 6

\title{
Change of Soil Surface Roughness of Splash Erosion Process
}

\author{
Zicheng Zheng and Shuqin He \\ Additional information is available at the end of the chapter \\ http://dx.doi.org/10.5772/51278
}

\section{Introduction}

Soil erosion is a common global environmental problem and undermines sustainable development in various economies and societies. Detailed information about changes in surface roughness during the whole soil erosion process remains limited, however, due to practical difficulties in obtaining direct soil microrelief measurements (Huang, 1998) and a lack in systematic research. The Chinese Loess Plateau is one of the most severely eroded regions in the world, which has created many environmental problems along the lower reaches of the Yellow River. Despite this, however, very little erosion-based research has been conducted on the Loess Plateau. Erosion and runoff processes are influenced mainly by soil surface characteristics such as soil surface roughness, cohesion, and granular stability. Among these characteristics, soil surface roughness is a key parameter (Gómez, and Nearing, 2005; Mirzaei et al., 2008), and is used to describe the variation in surface elevation across a field. The soil surface micro-topography or roughness is strongly influenced by agricultural activities, together with soil properties and climate. The term soil roughness was used to describe disturbances or irregularities in the soil surface at a scale which was generally too small to be captured by a conventional topographic map or survey. Soil surface roughness is an important parameter in understanding the mechanisms of soil erosion by water and wind. Many erosion related surface processes, such as depression water storage, raindrop or wind shear detachment, and sediment transport have characteristic lengths in millimeter scales. Thus, soil surface roughness resulting from small scale elements is important in understanding these processes and their spatial variation (Huang and Bradford, 1990). Soil surface roughness determines the storage of water on the soil surface and may indirectly influence its infiltration capacity. The velocity of overland flow is controlled by the hydraulic resistance of the soil surface. Soil surface roughness affects the organization of the drainage pattern on 
the field and the catchments scale, which in turn may have important implications for the spatial distribution of sediment sources and sinks. Conversely, some of these processes affect surface roughness. Most of the literature on soil surface roughness focusing on its mathematical description and on how it changes under rainfall(Linden and Van doren,1986; Römkens and Wang,1987; Lehrsch et al,1988; Bertuzzi et al.,1990).Soil surface roughness significantly impacts runoff and sediment generation under rainfall in several different ways.

It was one kind of erosion phenomenon which the raindrop strikes the soil surface to create the soil particle dispersion and the leap moves for the splash erosion. It was one of the important components to soil erosion (Wang et al,1997, 1999; Zhao and Wu,2001; Liu and Wu,1996;Wu, 1999; Wu and Zhou,1994). The kinetic energy which the raindrop dropped from airborne was the higher than that of sheet flow and erosion sediment during the rainfall runoff for the different soil surface (Huang,1983). According to the observation data of some researches, the soils of bare land by the raindrop scattered were 10 times than those of the laminar flow scoured (Cai et al,1998). Many authors have studied the effect of rainfall on soil surface roughness and developed models to describe the change of soil surface roughness. Some researches obtained the simple forecast model of soil surface roughness (Johson et al,1979; Onstad,1984; Steichen, 1984). Later, the widely accepted concept of decreasing roughness with increasing amount of rainfall or rainfall energy may not always be appropriate. After $63 \mathrm{~mm}$ of rainfall the surface was crusted and surface roughness was decreased. However, an additional $92 \mathrm{~mm}$ of rainfall appeared to have a higher roughness value (Huang and Bradford,1992).

The objective of this study was to focus on the relationship between soil surface roughness and splash erosion. First, soil surface roughness affected on splash erosion under the condition of rainfall. Second, how was the change of soil surface roughness during the period of rainfall?

\section{Material and Methods}

\subsection{Soil and soil box design}

Experiments were carried out at the Northwest AF University Soil Erosion Research Laboratory, Yangling town,China. The soil was collected from the topsoil soil $(0-20 \mathrm{~cm})$ in Yangling town. Basic properties of soil were following (Table 1).

\begin{tabular}{cccccc}
\hline \multicolumn{6}{c}{ Particle size/ (\%) } \\
\hline$>0.25 \mathrm{~mm}$ & $0.25-0.05 \mathrm{~mm}$ & $0.05-0.01 \mathrm{~mm}$ & $0.01-0.005 \mathrm{~mm}$ & $0.005-0.001 \mathrm{~mm}$ & $<0.001 \mathrm{~mm}$ \\
\hline 0.12 & 2.70 & 41.13 & 6.88 & 12.89 & 36.28 \\
\hline
\end{tabular}

Table 1. Particle size distribution $(0-20 \mathrm{~cm})$ of experimental soil.

Four iron boxes of $2.0 \mathrm{~m} \times 1.0 \mathrm{~m} \times 0.5 \mathrm{~m}$ were used in the rainfall simulation study. Air-dried top soil was passed through a $10 \mathrm{~mm}$ sieve to insure homogeneity and placed in every erosion box with an area of $2 \mathrm{~m}^{2}$. The soil bulk density was controlled to $1.08 \mathrm{~g} \mathrm{~cm}^{-3}$ in order to 
assure to fill to be homogeneous and close natural state through randomization method. Before the rainfall, the soil mechanical composition was measured by the pipette method, and the soil bulk density was measured by the ring sampler method.

\subsection{Rainfall simulations and soil surface roughness measurement techniques}

Rainfall/erosion methods in this lab study were similar to those described by Zheng et al. (2007). The soil box was adjusted at 150 slope gradient and then placed under a rainfall simulator with oscillating nozzles. Rainfall high was $2.7 \mathrm{~m}$ and effective rainfall area approximately was $20 \mathrm{~m}^{2}$. This experiment used the constant rainfall intensity, therefore, different rainfall intensities were rated before testing. The uniformity of rainfall was up to 0.90 . Development of micro-relief was monitored by recording soil surface at the beginning and at the end of the experiments, using the non-contact profile laser scanner measuring instrument specified and calculated (Zheng,2007). The maximum range of detectable elevation differences was approximately $500 \mathrm{~mm}$. Surface relief was measured point by point in a regularly spaced grid. The maximum scanning area was $2 \mathrm{~m}$. The surface roughness was measured for each soil box before the rainfall and after the rainfall separately with non-contact the profile laser scanner.

Simulated rainfall for each replication of a treatment were divided into the single rainfall intensity and the combined rainfall intensity, the parameters of single rainfall intensity respectively were $0.68 \mathrm{~mm} / \mathrm{min}$ and $1.50 \mathrm{~mm} / \mathrm{min}$, the parameter of combined rainfall intensity is $0.68 \mathrm{~mm} / \mathrm{min}, 1.00 \mathrm{~mm} / \mathrm{min}$ and $1.50 \mathrm{~mm} / \mathrm{min}$. The above experiments had three repeats. Each experiment started on a freshly prepared surface for each replication of a treatment. The rainfall simulation duration were depended on the change of soil surface.

\subsection{Management treatments}

The four artificial management measures were designed according to the local agriculture custom in Loess Plateau, because agriculture management measures were mainly artificial management. The four artificial management measures were the raking cropland (PM), the artificial hoe $(\mathrm{CH})$, the artificial dig (TW) and the contour slope (DG).They were used to simulate different types of soil surface roughness separately, the straight slope $(\mathrm{CK})$ was taken to the control.

\subsection{Splash erosion}

The amounts of splash erosion were collected through the hanging splash erosion board and measured by the oven drying method. The width to the hanging splash erosion board was $1 \mathrm{~m}$ and the height was $0.5 \mathrm{~m}$. The hanging splash erosion board was installed in the middle of the soil box was to be used to collect splashing soil during the experiments(Fig.1).

At the same time, raindrops of every rainfall were collected to calculate raindrop diameter. Raindrop diameter was measured through the color spot method according the B.Z.Dou et.al (Dou and Zhou,1982; Zheng and Gao,2000), the formula was as following:

$$
d=0.356 D^{0.712}
$$


where $\mathrm{d}$ is the raindrop diameter of every rainfall $(\mathrm{mm}), \mathrm{D}$ is the color spot diameter $(\mathrm{mm})$.

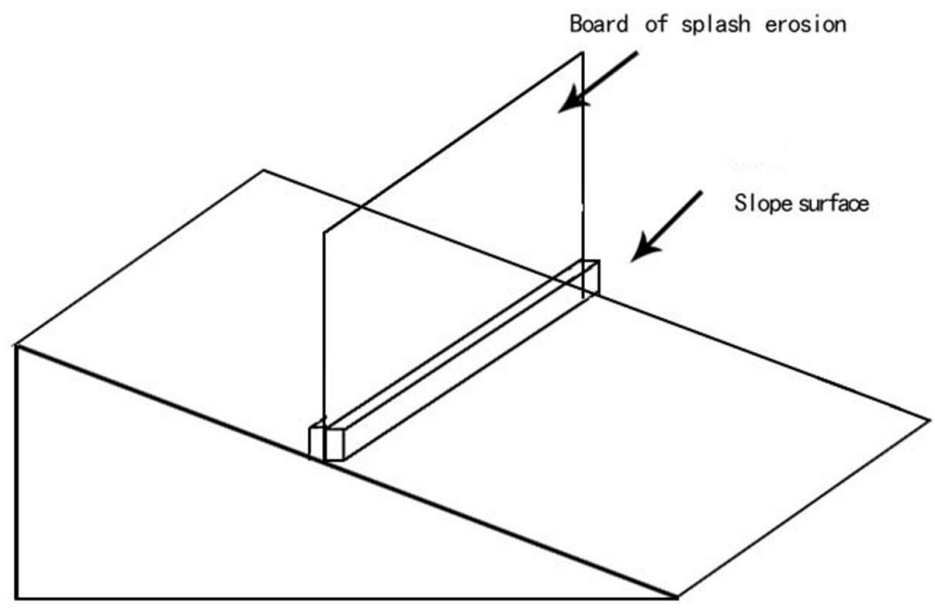

Figure 1. Collecting board of splash erosion.

\section{Results and Discussion}

\subsection{Changing characteristics of soil surface roughness on the single rainfall intensity}

The changing characteristics of soil surface roughness had complicated relatively under the different rainfall intensity (Table.2). The soil surface roughness increased on the CK slope under the rainfall intensity of $0.68 \mathrm{~mm} / \mathrm{min}$. The soil surface roughness decreased on the CK slope under the rainfall intensity of $1.50 \mathrm{~mm} / \mathrm{min}$. On the PM slope, the changing characteristics of soil surface roughness was consistent with the CK slope, however, changing characteristics of soil surface roughness decreased on the other slopes under the rainfall intensity of $0.68 \mathrm{~mm} / \mathrm{min}$. Under the rainfall intensity of $1.50 \mathrm{~mm} / \mathrm{min}$, the changing characteristics of soil surface roughness with other slopes were contrary with the CK and showed increasing trends.

The reasons of the above results were the interaction among raindrop kinetic energy, soil surface roughness and splash amount possibly. From the angle of physics, the function of raindrop to the soil surface was one kind of acting process actually. The raindrop would hit and compact exposed soil surface when the rainfall began. At the same time, infiltrate ability of the soil reduced and soil bulk density increased gradually, and the partial soil was easy to form the crust due to soil surface fine-grain inserting in former place or migration and jamming soil pore space. Thus, soil surface roughness and the splash amounts also changed. 


\begin{tabular}{|c|c|c|c|c|}
\hline Tillage practice & $\begin{array}{l}\text { Rainfall intensity/ } \\
\mathrm{mm} \cdot \mathrm{min}^{-1}\end{array}$ & $\mathrm{R}_{0} / \mathrm{cm}$ & $\mathrm{R} / \mathrm{cm}$ & $\mathbf{R} / \mathbf{R}_{0}$ \\
\hline \multirow{2}{*}{ Straight slope (CK) } & 0.68 & \multirow{2}{*}{0.201} & 0.235 & 1.169 \\
\hline & 1.50 & & 0.193 & 0.960 \\
\hline \multirow{2}{*}{ Raking cropland (PM) } & 0.68 & \multirow{2}{*}{0.240} & 0.246 & 1.024 \\
\hline & 1.50 & & 0.268 & 1.115 \\
\hline \multirow{2}{*}{ Artificial hoe $(\mathrm{CH})$} & 0.68 & \multirow{2}{*}{0.706} & 0.654 & 0.926 \\
\hline & 1.50 & & 0.732 & 1.036 \\
\hline \multirow{2}{*}{ Artificial dig (TW) } & 0.68 & \multirow{2}{*}{0.812} & 0.701 & 0.864 \\
\hline & 1.50 & & 0.874 & 1.077 \\
\hline \multirow{2}{*}{ Contour slope (DG) } & 0.68 & \multirow{2}{*}{1.633} & 1.576 & 0.965 \\
\hline & 1.50 & & 1.707 & 1.045 \\
\hline
\end{tabular}

Note: $R_{0}$-soil surface roughness before rainfall, $\mathrm{cm} R$ - soil surface roughness after rainfall, $\mathrm{cm}$. The same bellow.

Table 2. Change of soil surface roughness on the single rainfall intensity.

Relationships between rainfall energy and soil surface roughness were obtained by the method of statistics and analysis. The results followed:

Under the rainfall intensity of $0.68 \mathrm{~mm} / \mathrm{min}: R_{1} / R_{0}=49261 \mathrm{E}^{-3.3451} \mathrm{r}=0.817 \mathrm{n}=15$

Under the rainfall intensity of $1.50 \mathrm{~mm} / \mathrm{min}: R_{1} / R_{0}=2 \times 10^{6} \mathrm{E}^{-4.2309} \mathrm{r}=0.836 \mathrm{n}=15$

where $R_{1}$ is the soil surface roughness after rainfall $(\mathrm{cm}), R_{0}$ is the soil surface roughness before rainfall $(\mathrm{cm}), \mathrm{E}$ is the total kinetic energy of raindrop $\left(\mathrm{J} / \mathrm{cm}^{2} \mathrm{~min}\right), \mathrm{n}$ is the sample number.

They had the power function relationship between the change of the soil surface roughness and kinetic energy of raindrop under the different rainfall intensities. Soil surface roughness decreased with the increasing kinetic energy of raindrop. The results had the consistent with Burwell (1969) and Steichen (1984).

\subsection{Changing characteristics of soil surface roughness under the combined rainfall intensity}

The combined rainfall intensity was be simulated in order to clear about the change and nature of soil surface roughness. The changing characteristics of soil surface roughness were different for the different slopes under the combined rainfall intensity (Table.3). The changing characteristics of soil surface roughness increased first, and then decreased, and increased finally with the increasing rainfall intensity on the CK slope. However, the changing characteristics of soil surface roughness increased on the PM slope, and the change of soil surface roughness increased first and then decreased on other slopes with the increasing rainfall intensity. 


\begin{tabular}{|c|c|c|c|}
\hline Tillage practice & Rainfall intensity $/ \mathrm{mm} \cdot \mathrm{min}^{-1}$ & $R_{0} / \mathrm{cm}$ & $\mathrm{R} / \mathrm{cm}$ \\
\hline \multirow{3}{*}{ Control slope (CK) } & 0.68 & \multirow{3}{*}{0.201} & 0.235 \\
\hline & 1.00 & & 0.222 \\
\hline & 1.50 & & 0.302 \\
\hline \multirow{3}{*}{ Raking cropland (PM) } & 0.68 & \multirow{3}{*}{0.240} & 0.246 \\
\hline & 1.00 & & 0.283 \\
\hline & 1.50 & & 0.319 \\
\hline \multirow{3}{*}{ Artificial hoe $(\mathrm{CH})$} & 0.68 & \multirow{3}{*}{0.706} & 0.654 \\
\hline & 1.00 & & 0.624 \\
\hline & 1.50 & & 0.625 \\
\hline \multirow{3}{*}{ Artificial dig (TW) } & 0.68 & \multirow{3}{*}{0.812} & 0.701 \\
\hline & 1.00 & & 0.586 \\
\hline & 1.50 & & 0.614 \\
\hline \multirow{3}{*}{ Contour slope (DG) } & 0.68 & \multirow{3}{*}{1.633} & 1.576 \\
\hline & 1.00 & & 1.572 \\
\hline & 1.50 & & 1.577 \\
\hline
\end{tabular}

Table 3. Change of soil surface roughness under the combined rainfall intensity.

The reasons of the above results were the interaction between raindrop kinetic energy and soil surface roughness. The micro-relief of CK slope and PM slope were relatively small in the initial period of the rainfall. At the same time, the raindrop impact was relatively even, and they had the positive relationship between the raindrop kinetic energy and the rainfall intensity. Therefore, the changing characteristics of soil surface roughness increased and the raindrop impact gradually strengthened with the increasing rainfall intensity for the CK slope and PM slope. However, the micro-relieves of other slopes were relatively obvious in the initial period of the rainfall. At the same time, the convex fraction of raindrop impact was splashed and the concave fraction of raindrop impact was padded by other soil particle, and the part of the concave appeared the crust. So, the soil surface roughness decreased in the initial period of the rainfall. The partial soil particle of surface was dispersed or migrated, caused soil surface roughness to increase with the continuous the function of raindrop impact.

The changing characteristics of soil surface roughness were decided on the initial soil surface condition and the surface dynamic process of rainfall. The changing characteristics of soil surface roughness were analyzed with the impact of accumulating rainfall amount under the combined rainfall intensity in order to clarify the change of soil surface roughness. The results followed as Fig. 2.

Relationships between the accumulated rainfall amount and the change of soil surface roughness were obtained by the method of statistics and analysis. 


$$
R / R_{0}=-6 \times 10^{-6} P^{3}+0.0012 P^{2}-0.0768 P+2.3629 r=0.708 ; n=15
$$

where $R_{1}$ is the soil surface roughness after rainfall(m), $R_{0}$ is the soil surface roughness before rainfall $(\mathrm{m}), P$ is the accumulated rainfall amount $(\mathrm{mm}), \mathrm{n}$ is the sample number.

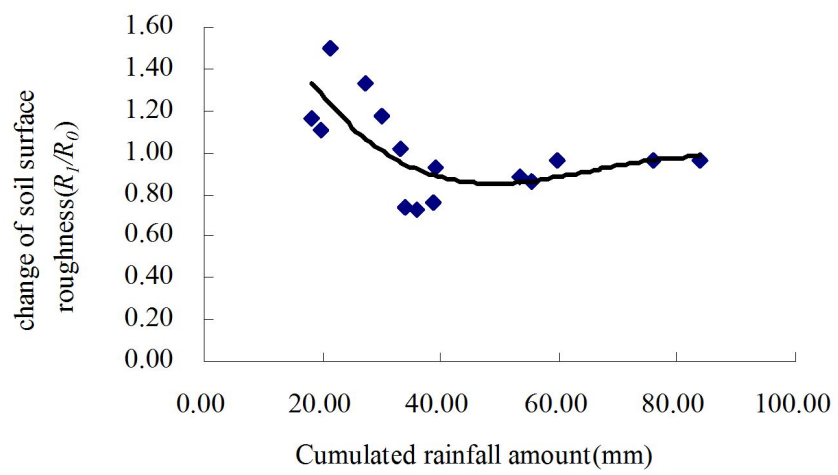

Figure 2. Relationship between change of soil surface roughness and cumulated rainfall amount.

The changing characteristics of soil surface roughness increased first and then decreased for all the slops with the increasing accumulated rainfall amount.

\subsection{Relationship between the changing of soil roughness and splash erosion amount}

Table. 4 shows the splash erosion amounts of all tillage practices under the different rainfall intensities.

\begin{tabular}{ccc}
\hline Tillage practice & $\begin{array}{c}\text { Rainfall intensity/ } \\
\mathbf{m m} \cdot \mathbf{m i n}^{-1}\end{array}$ & $\begin{array}{c}\text { Splash erosion amounts / } \\
\mathbf{g} \cdot \mathbf{c m}^{-\mathbf{2}}\end{array}$ \\
\hline \multirow{2}{*}{ Control slope (CK) } & 0.68 & 0.10 \\
& 1.50 & 0.57 \\
\hline \multirow{2}{*}{ Raking cropland (PM) } & 0.68 & 0.93 \\
\cline { 2 - 3 } & 1.50 & 1.18 \\
\hline \multirow{2}{*}{ Artificial hoe (CH) } & 0.68 & 1.27 \\
\cline { 2 - 3 } Artificial dig (TW) & 1.50 & 1.46 \\
Contour slope (DG) & 0.68 & 0.61 \\
& 1.50 & 1.09 \\
& 0.68 & 0.81 \\
\hline
\end{tabular}

Table 4. Splash erosion amounts under the different rainfall intensities. 
The change of splash erosion amounts had the difference under the different rainfall conditions on the all the slopes. The splash erosion amounts of the CK slope were lower than those of other slopes under the rainfall intensity of $0.68 \mathrm{~mm} / \mathrm{min}$ and $1.50 \mathrm{~mm} / \mathrm{min}$ (Table.4).

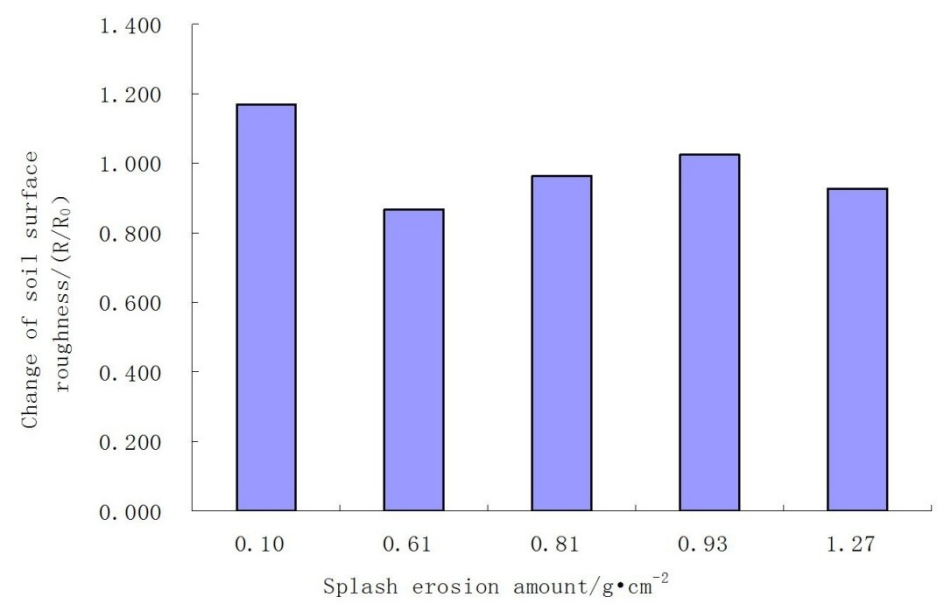

(a) $\mathrm{I}=0.68 \mathrm{~mm} / \mathrm{min}$

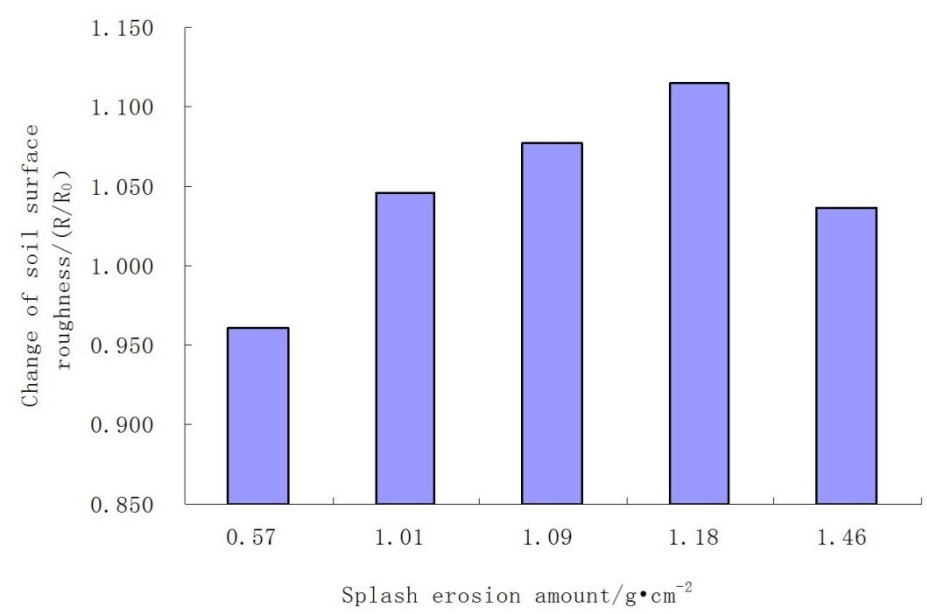

(b) $\mathrm{I}=1.50 \mathrm{~mm} / \mathrm{min}$

Figure 3. Relationship between soil surface roughness and splash erosion amounts under the different rainfall intensities.

The change of soil surface roughness showed the different characteristic with the splash erosion amounts under the different rainfall conditions for the all the tillage practices. The 
splash erosion amounts of the CK slope were lower than those of other slopes under the rainfall intensity of $0.68 \mathrm{~mm} / \mathrm{min}$, but the change of soil surface roughness was the highest (Fig.3a). However, the splash erosion amounts of the CK slope were lower than those of other slopes under the rainfall intensity of $1.50 \mathrm{~mm} / \mathrm{min}$, and the change of soil surface roughness was the lowest (Fig.3b).

The change of soil surface roughness increased first and then decreased for other slopes with the increasing splash erosion amounts under the rainfall intensity of $0.68 \mathrm{~mm} / \mathrm{min}$ and 1.53 $\mathrm{mm} / \mathrm{min}$. The above results were caused the interaction of raindrop kinetic energy and soil surface fluctuation condition. The raindrop impact to rainfall intensity of $1.50 \mathrm{~mm} / \mathrm{min}$ was obviously stronger than that of the rainfall intensity of $0.68 \mathrm{~mm} / \mathrm{min}$, and soil particles of former sites were sputtered. In turn, the around particle of the former sites might supplied soil particles through the same action. The soil particles of the continuous supplement might also supply the material base for the migration. The unceasing replacement would cause the interaction of soil surface roughness and splash erosion. So, the results were quite complicated.

\section{Conclusions}

Under the rainfall intensity of $0.68 \mathrm{~mm} / \mathrm{min}$, the soil surface roughness increased on the control slope, the changing characteristics of soil surface roughness to the raking cropland slope was consistent with the control slope, however change of soil surface roughness to the other slopes decreased. The splash erosion amounts of the control slope were lower than those of other slopes, but the change of soil surface roughness was the highest. Under the rainfall intensity of $1.50 \mathrm{~mm} / \mathrm{min}$, the soil surface roughness decreased on the control slope, the change of soil surface roughness showed increasing trends on the other slopes. The splash erosion amounts of the control slope were lower than those of other slopes, and the change of soil surface roughness was the lowest. Under the combined rainfall intensity, the change of soil surface roughness of the control slope increased first, and then decreased, and increased finally with the increasing rainfall intensity. The change of soil surface roughness increased on the raking cropland slope, and the change of soil surface roughness increased first and then decreased for other slopes with the increasing rainfall intensity.

\section{Acknowledgements}

The research was supported by the National Natural Science Foundation of China (Grant No. 40901138),National Basic Research Program of ChinaGrant No. 2007CB407201 and also supported by State Key Laboratory of Soil Erosion and Dryland Farming on the Loess PlateauInstitute of Water and Soil ConservationChinese Academy of Sciences and Ministry of Water Resources (Grant No. 10501-283). 


\section{Author details}

Zicheng Zheng ${ }^{1,2^{*}}$ and Shuqin $\mathrm{He}^{1,2}$

*Address all correspondence to: zichengzheng@yahoo.com.cn

1 College of Resource and Environment, Sichuan Agriculture University

2 State Key Laboratory of Soil Erosion and Dryland Farming on the Loess Plateau Institute of Water and Soil Conservation Chinese Academy of Sciences and Ministry of Water Resources, China

\section{References}

[1] Bertuzzi, R., Rouws, G., \& Couroult, D. (1990). Testing roughness indices to estimate soil surface roughness changes due to simulated rainfall. Soil Tillage Res., 17, 87-99.

[2] Burwell, R. E., \& Larson, W. E. (1969). Infiltration as influenced by tillage-induced random roughness and pore space. Soil Sci. Soc. Am. Proc., 33, 449-452.

[3] Cai, Q. G., Wang, G. G., \& Chen, Y. Z. (1998). Process and simulate of sediment in small watershed of Loess Plateau, Beijing, Science Press.

[4] Dou, B. Z., \& Zhou, P. H. (1982). Method of measure and mathematics to raindrop. Bulletin of Soil and Water Conservation, 2(1), 44-47.

[5] Go'mez, J. A., \& Nearing, M. A. (2005). Runoff and sediment losses from rough and smooth soil surfaces in a laboratory experiment. Catena, 59, 253-266.

[6] Huang, C. H. (1998). Quantification of soil microtopography and surface roughness. Fractals in soil scienceIn: Baveye, P., Parlange, J.Y., Eds. B.A.Stewart. Advances in Soil Science, CRC.

[7] Huang, Bingwei. (1983a). Problems of soil conservation in the middle of Yellow River. Soil and Water Conservation in China [1], 8-13.

[8] Huang, C. H., \& Bradford, J. M. (1990). Depressional storge for Markor-Gaussian surfaces. Water Resources Research, 26, 2235-2242.

[9] Huang, C. H., \& Bradford, J. M. (1992). Applications of a laster scanner to quantify soil microtopogrophy. Soil Sci. Soc. Am. J, 56(1), 14-21.

[10] Johnson, C. B., Mannering, J. V., \& Moldenhauer, W. C. (1979). Influence of surface roughness and clod size and stability on soil and water losses. Soil Sci. Soc. Am. J, 43, 772-777.

[11] Lehrsch, G. A., Whisler, F. D., \& Romkens, M. J. M. (1987). Soil surface roughness as influenced by selected soil physical properties. Soil Tillage Res., 10, 197-212. 
[12] Linden, D. K., Van , D. M., \& Doren, J. R. (1986). Parameter for characterizing tillageinduced soil surface roughness. Soil. Sci. Soc. Am. J, 50, 1561-1565.

[13] Liu, Bingzheng., \& Wu, Faqi. (1996). Soil Erosion, Xi'an, People Press of Shannxi.

[14] Mirzaei, M. R., Ruy, S., Ziarati, T., Khaledian, M. R., \& Christina, B. (2008). Changes of soil surface roughness under simulated rainfall evaluated by photogrammetry. Geophysical Research Abstracts, 10, EGU2008A-02576.

[15] Onstad, C. A. (1984a). Depressional storage on tilled soil surfaces. Trans. Am. Soc. Agric. Eng., 27, 729-732.

[16] Romkens, M. J. M., \& Wang, J. Y. (1987). Soil roughness changes of tillage system from rainfall. Trans. Am. Soc.of Agric. Eng., 30, 101-107.

[17] Steichen, J. M. (1984). Infiltration and random roughness of a tilled and untilled clay pan soil. Tillage Res, 4, 251-262.

[18] Wang, X. K., Ao, R. Z., \& Yu, G. L. (1999). Rainsplash erosion and its sediment transport capacity on slope. Journal of Sichuan University, 3(2), 7-12.

[19] Wang, X., \& Fang, D. (1997). A physically-based model of rainsplash erosion on the slope. Journal of Sichuan University, 1(3), 90-102.

[20] Wu, F. Q. (1999). Analysis and study on erosion rainfall and productivity of gently sloping farmland, Yangling, Institute of Soil and Water Conservation.

[21] Wu, P. T., \& Zhou, P. H. (1994). The Effects of Raindrop Splash on the Sheet FlowHydraulic Friction Factor. Journal of Soil Water Conservation, 8(2), 40-42.

[22] Zhao, X. G., \& Wu, F. Q. (2001). Single raindrop splash law and its selection role on soil particles splashed. Journal of Soil Water Conservation, 15(1), 43-45, in Chinese.

[23] Zheng, F. L., \& Gao, X. T. (2000). Process and simulate of soil erosion of Loess slope, Xi'an, People Press of Shannxi.

[24] Zheng, Z. C. (2007). Study on the effect and change characteristic of soil surface roughness during the course of water erosion, Yangling, Northwest Agricultural and Forestry University. 
